\section{HUMANAS E SOCIAIS}

V.9 • N.2 • 2021 • Fluxo Contínuo

ISSN Digital: 2316-3801

ISSN Impresso: 2316-3348

DOI: $10.17564 / 2316-3801.2021 v 9 n 2 p 6-16$

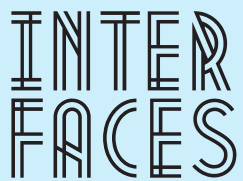

CIENTÍFICAS

\title{
QUESTÕES DE GÊNERO E SEXUALIDADE EM SUA DIMENSÃO PRAGMÁTICA COM A EDUCAÇÃO NA CONTEMPORANEIDADE
}

GENDER AND SEXUALITY ISSUES IN THEIR PRAGMATIC DIMENSION WITH CONTEMPORARY EDUCATION

\section{LAS CUESTIONES DE GÉNERO Y SEXUALIDAD EN SU DIMENSIÓN PRAGMÁTICA CON LA EDUCACIÓN CONTEMPORÁNEA}

Mara Dantas Pereira ${ }^{1}$

Míria Dantas Pereira ${ }^{2}$

Dinamara Garcia Feldens ${ }^{3}$

\section{RESUMO}

No cenário contemporâneo, questões sobre gênero e sexualidade têm sido objeto de discussões e debates em diversos aspectos, abordagens de pensamento e concepções, demonstrando a importância de estudos como este no âmbito da educação. Diante disso, propôs-se realizar uma revisão da literatura sobre questões de gênero e sexualidade diante da dimensão pragmática com a educação. Além disto, discutir sobre a inserção de políticas públicas na escola, evidenciando seus desafios para implementação no cenário educacional. Como procedimento metodológico, optou-se por uma revisão narrativa da literatura com busca de artigos indexados nas bases de dados: ERIC, LATINDEX, REDALYC e SciELO. Por fim, diante das reflexões tecidas no estudo, foi possível compreender a importância de políticas de equidade, a fim de promover um ambiente escolar mais saudável para todos os indivíduos envoltos no processo de ensino e aprendizagem, e que as escolas têm o poder de preparar os estudantes para se tornarem sujeitos ativos e críticos, promovendo a construção de uma sociedade menos desigual.

\section{PALAVRAS-CHAVE}

Gênero. Sexualidade. Educação. 


\section{ABSTRACT}

In the contemporary scenario, questions about gender and sexuality have been the subject of discussions and debates in several aspects, approaches to thinking and conceptions, demonstrating the importance of studies like this in the scope of education. Therefore, it was proposed to carry out a literature review on gender and sexuality issues in view of the pragmatic dimension with education. In addition, discuss the insertion of public policies in the school, highlighting its challenges for implementation in the educational scenario. As a methodological procedure, we opted for a narrative review of the literature with a search for articles indexed in the databases: ERIC, LATINDEX, REDALYC and SciELO. Finally, given the reflections made in the study, it was possible to understand the importance of equity policies, in order to promote a healthier school environment for all individuals involved in the teaching and learning process, and that schools have the power to prepare students to become active and critical subjects, promoting the construction of a less unequal society.

\section{KEYWORDS}

Genre. Sexuality. Educatio

\section{RESUMEN}

En el escenario contemporáneo, las preguntas sobre género y sexualidad han sido objeto de discusiones y debates en varios aspectos, enfoques de pensamiento y concepciones, lo que demuestra la importancia de estudios como este en el ámbito de la educación. Por lo tanto, se propuso llevar a cabo una revisión de la literatura sobre cuestiones de género y sexualidad en vista de la dimensión pragmática con la educación. Además, discutir la inserción de políticas públicas en la escuela, destacando sus desafíos para la implementación en el escenario educativo. Como procedimiento metodológico, optamos por una revisión narrativa de la literatura con una búsqueda de artículos indexados en las bases de datos: ERIC, LATINDEX, REDALYC y SciELO. Finalmente, dadas las reflexiones hechas en el estudio, fue posible comprender la importancia de las políticas de equidad, para promover un ambiente escolar más saludable para todas las personas involucradas en el proceso de enseñanza y aprendizaje, y que las escuelas tienen el poder de preparar estudiantes para que conviértanse en sujetos activos y críticos, promoviendo la construcción de una sociedad menos desigual.

\section{PALABRAS CLAVE}

Género. Sexualidad. Educación. 


\section{INTRODUÇ̧̃̃o}

As temáticas pautadas a questões de gênero e sexualidade em espaços escolares têm sido objeto de diversos debates e de discussões em diferentes abordagens de pensamento, enfoques e concepções, despertando a relevância de estudos sobre elas e de como as políticas públicas educacionais têm reagido a esses temas.

Entretanto, rapidamente, estes discursos e formas de controle são modificados, de modo que a sociedade evolui a luz de novos discursos que são construídos, e com eles novas práticas sociais são produzidas e reproduzidas com o decorrer dos anos. Desta forma, é necessária uma constante atualização sobre as recorrentes mudanças deste cenário.

À face do exposto, propôs-se realizar uma revisão da literatura sobre questões de gênero e sexualidade diante da dimensão pragmática com a educação. Além disto, discutir sobre a inserção de políticas públicas na escola, evidenciando seus desafios para implementação no cenário educacional.

Historicamente, a aproximação entre os termos 'gênero', 'sexualidade' e 'escola' vem trazendo discussões que destacam esses paradigmas desde o século XIX (PROBST; KRAEMER, 2020). Os autores Almeida, Vale e Silva (2020) refletem sobre o papel social da escola, no qual a define como espaço democrático que deve possibilitar debates sobre questões sociais e propiciar a construção de pensamento crítico. Além, de um ambiente de sociabilização entre as crianças e adolescentes, o que gera a difusão sociocultural, envolvendo as relações de gênero e sexualidade.

As políticas públicas educacionais devem buscar a implementação de estratégias e ações para a promoção da equidade de gênero, identidade de gênero e orientação sexual, além da confrontação ao sexismo e à homofobia. Não podendo deixar de salientar, que a sexualidade atualmente é vista como um problema de saúde pública, estando o contexto da escola como um local privilegiado para implementar ações que promovam a saúde de crianças, adolescentes e jovens (BORGES; ROSSI, 2019).

Nesse sentido, deve haver nos espaços escolares uma constante abertura a pautas de questões de gênero e sexualidade. Desta maneira, esse processo iniciou-se, por meio de novas propostas curriculares, implementadas pelo Ministério da Educação (MEC) em 1998, com os Parâmetro Curriculares Nacionais (PCN). Este documento traz um olhar complexo sobre a sexualidade. Dessa forma, o documento traz diversas fundamentações e auxílios teóricos com o objetivo de incluir o tema da equidade de gênero nos conteúdos curriculares (SOARES; CHAVES; FÉLIX, 2019; REMÍDIO; SILVA; MEIRELES, 2019).

\section{A INSERÇÃO DE QUESTÕES DE GÊNERO E SEXUALIDADE NAS POLÍTICAS PÚBLICAS: DESAFIOS CONTEMPORÂNEOS}

As políticas públicas, em geral são projetadas como deveres do estado por defluência da determinação dos direitos fundamentais. A cláusula do estado social e democrático de direito estende a proteção e dirige aos poderes públicos a incumbência de garantir aos cidadãos as circunstâncias 
mínimas e eficientes para uma vida digna, proporcionando o desenvolvimento livre de sua personalidade (FERRAZ; ADDOR; NASCIMENTO NETO, 2019).

Assim sendo, as confluências entre gênero e políticas públicas surgiram de várias formas, obtendo visibilidade nos estudos relacionados a área da educação na década de 1990, com o foco centralizado em políticas para diminuição da discriminação contra mulheres (SOARES; CHAVES; FÉLIX, 2019).

Compreende-se que sexualidade e o gênero estão incursos no cotidiano da vida em sociedade, estando presentes em todos os contextos, inclusive nos espaços escolares e em seus currículos (REMÍDIO; SILVA; MEIRELES, 2019).

Historicamente, na década de 1980, as demandas de cunho sexuais se agravaram, pelo surgimento do Vírus da Imunodeficiência Humana (VIH/AIDS), e aumentou da incidência de Doenças Sexualmente Transmissíveis (DST). Desse modo, pela perspectiva formativa da escola, a "educação sexual" passou a ser promovida nos meios oficiais educacionais, com o intuito de inserir debates por meio da elaboração de trabalhos sobre sexualidade, dos quais as principais temáticas presentes foram à prevenção da gravidez precoce e da infecção pelo VIH/Aids e demais DST (BRABO; SILVA; MACIEL, 2020).

Dentro deste universo dialógico, é significativo realçar que as questões de gênero expõem diferentes fatos da vida humana, cujos dilemas sociais vêm juntamente com desigualdades, homofobia, sexismo entre outros, provocando, assim, reações, eminentemente, na escola. Deste modo, as discriminações e os preconceitos no âmbito da escola envolvem por intermédio da ação e assim como a negligência, agindo de maneira diferente entre alunas e alunos (OLIVEIRA; DIAS, 2019).

Prontamente, para que sejam capazes de discutir sobre estas temáticas de forma crítica e fundamentada, torna-se fundamental que sejam problematizados alguns de seus aspectos constitutivos. Todavia, foi pela via da exclusão que eles apareceram, ocorrendo mais mudanças relativas às temáticas de gênero e de sexualidade nos documentos curriculares, nesta ocasião na redação final da Base Nacional Comum Curricular (BNCC) (CARDOSO et al., 2019).

É importante lembrar que o eixo basilar das políticas educacionais, que buscaram inserir as temáticas de gênero e sexualidade, foi o currículo, com ênfase para os PCN e formação docente, este último obtém grande incentivo a partir do Programa Brasil sem Homofobia (BSH). Conforme Soares (2019, p. 6) vale salientar que:

$\mathrm{O}$ BSH, programa de combate à violência e à discriminação contra LGBTs e de promoção da cidadania homossexual, teve como objetivo promover a cidadania de gays, lésbicas, travestis, transgêneros e bissexuais, a partir da equiparação de direitos e do combate à violência e à discriminação homofóbicas, respeitando a especificidade de cada um desses grupos populacionais.

Nesse momento, é importante destacar de acordo com Soares, Chaves e Félix (2019, p. 102):

Como outro marco institucional significativa com a publicação do I Plano Nacional de Políticas para Mulheres (PNPM), em 2004 (e, posteriormente, dos II e III PNPM), o qual estabeleceu diretrizes para educação inclusiva e não sexista com objetivos nas seguintes 
áreas: inserção da perspectiva de gênero no processo educacional, a promoção de um sistema educacional não discriminatório, a preocupação especial com o acesso de mulheres na educação básica, a promoção da visibilidade das mulheres na história da humanidade e o combate aos estereótipos de gênero.

\section{MÉTODO}

O presente estudo é a decorrência de uma revisão narrativa da literatura sobre questões de gênero e sexualidade em sua dimensão pragmática com a educação na contemporaneidade, desenvolvido no período de fevereiro a abril de 2020. Sabe-se que a revisão da literatura é uma compreensão geral das mais importantes pesquisas que aplicam métodos explícitos e reproduzíveis (LUGOBONI et al., 2020).

As buscas ocorreram entre fevereiro e março de 2020 nas bases de dados Scientific Electronic Library Online (SciELO), Sistema de Información Científica Redalyc Red de Revistas Científicas de América Latina y el Caribe (REDALYC) e Sistema Regional de Información en Línea para Revistas Científicas de América Latina, el Caribe, España y Portugal (LATINDEX). Foram utilizados os seguintes descritores: "gênero"; "sexualidade" e "contemporaneidade".

Adicionou-se a este procedimento, a análise das referências bibliográficas dos artigos encontrados que evolvessem o objetivo deste estudo. A primeira etapa foi realizada a partir da leitura dos títulos e resumos dos artigos, procurou-se selecionar estudos que discutissem a relação entre gênero, sexualidade e escola no cenário atual, mediante as políticas públicas vigentes e quais são os desafios dos docentes frente a implementação destas, na sala de aula.

Diante disso, foram estabelecidos como critérios de inclusão: artigos publicados entre os últimos sete anos, dando ênfase aos cinco últimos anos. Posteriormente, na segunda etapa foram encontrados 102 artigos. Destes, somente 20 estudos entre os anos de 2015 a 2020, atendiam aos critérios de inclusão e foram selecionados.

\section{RESULTADOS E DISCUSSÃO}

Em relação à análise das produções acadêmicas sobre gênero no contexto das políticas públicas de educação, percebe-se distinções em relação às propostas de inclusão de gênero nos currículos das escolas, além da falta de ações que garantam a necessária implementação dos novos requisitos para a prática do docente nas escolas. Isto ocorre, principalmente, devido a uma divergência entre o currículo da teoria para prática.

Deste modo, discutir-se sobre gênero e sexualidade atualmente na escola, transformou-se um grande desafio mediante os avanços do conservadorismo e de projetos políticos conservadores que buscam vetar, de forma autoritária, seja qual for à probabilidade de refletir e tratar sobre assunto, ocorrendo até a criminalização de docentes por desenvolverem tais temas em sala de aula. 
Isto pode ser visto diante da progressão de projetos políticos como o “Escola Sem Partido”, que tem o objetivo de proibir o uso do termo "gênero" nas escolas, além de retirá-lo de planos curriculares municipais, estaduais e nacionais. Surge, então, uma política que perpassa todas as bases legais da legislação da educação do período de redemocratização até os dias de hoje, visto que o demérito das discussões sobre gênero e sexualidade atinge os princípios operados pelo direito de ensinar e aprender pela Constituição Federal de 1988 (DELFINO, 2020)através dos projetos de intervenção ministrados por bolsistas do PIBID nas escolas conveniadas à Universidade Federal de Alfenas (UNIFAL.

Convém observar que no contexto escolar situações, em torno de filas, grupos de trabalho, atividades físicas e brincadeiras são distinguidos por sexo, apontando como "para menino" ou "para menina”, o que fortifica a desigualdade no âmbito social. Já em associação com as relações de gênero no espaço escolar, o assunto é pouco relevante entre os docentes. Pois os olhares daqueles que compõe a escola (diretores, professores, coordenadores, entre outros) não é receptivo para esta temática no âmbito escolar (ARAUJO; ROSSI; TEIXEIRA, 2019).

Consideramos importante esclarecer que a educação, em termos de sua relação com gênero e sexualidade, apresenta um espaço para a realização de "corpos sexuados". A partir de questões associadas à sexualidade, que se encontram de forma progressiva presentes no cotidiano da escola de forma explícita ou implicitamente, isto é, constantemente uma educação sexual tem como sentido fundamental a manutenção da ordem social definida pelo gênero, distinguindo assim "normalidade" com heterossexualidade. Vale ressaltar a visão de gênero no ambiente escolar para os autores Seoane e Severino (2019, p. 1):

O gênero não é uma propriedade dos corpos, mas a soma dos efeitos que ocorrem neles, bem como nos comportamentos, relacionamentos e interações que o sujeito tem com o mundo exterior. Na escola, há uma experiência de gênero e uma série de autorrepresentações produzidas no assunto por práticas socioculturais, discursos e instituições dedicadas à produção de mulheres e homens.

Ademais, é preciso reconhecer a educação como locus estratégico para trabalhar a diversidade, por meio de políticas e novas diretrizes curriculares que garantam uma formação, visando questões de gênero e sexualidades para os professores de forma engajada. Neste sentido, ocasiona significativos subsídios que proporcionam pensar em novas práticas com nova direção para uma educação em sexualidade, capaz de compreender a eficácia do conceito de gênero como ferramenta teórica e política na reflexão a respeito das subalternidades, fazendo-se a escola um espaço promissor para uma educação em sexualidade (BORGES; ROSSI, 2019).

Ainda de acordo com Araujo, Rossi e Teixeira (2019), o ambiente pedagógico é segregado em dois períodos, estando um relacionado a metodologia de ensino e aprendizagem e outro à aflição da escola com temas relativos a valores morais e comportamentos. O segundo é menosprezado pela escola por completo. Em contrapartida, mesmo que na escola os estudantes não tenham a chance de vivenciar e trocar experimentações, e que as necessidades deles, por mais que aconteça a repressão, vão se manifestar e se opor às normas. A partir desta premissa, é preciso que os professores levem este assunto para suas salas de aula. 
Nos espaços escolares, o conservadorismo ainda tem restringido que a sexualidade e o gênero sejam debatidos de forma aberta na escola. Por consequência, esta omissão gera falta de conhecimentos nos jovens e colaboram para aumento de casos de gravidez indesejada, contaminação por meio de DST, favorecendo para as relações sexuais desprotegidas, inclusive, dificultam a percepção dos jovens sobre as identidades e diversidade sexuais presentes, sustentando o preconceito ou opiniões equivocadas (TRENTIM; VIEIRA, 2019).

Neste contexto, é importante reconhecer que durante a formação profissional docente, a práxis entre gênero e sexualidade é de fundamental importância, em razão disso, é relevante que haja investimento nos processos de reflexão sobre as ações pedagógicas realizadas no contexto escolar.

Inclusive, deve-se mencionar a conduta discriminatória de alguns docentes e dos demais profissionais na escola em relação às manifestações sexuais dos estudantes. Pois, é possível evidenciar que parte dos docentes não recebem capacitação necessária para lidar com essas temáticas, reforçando a generalização de propostas pedagógicas sustentadas por concepções heteronormativas, religiosas e higienistas (FURLANETTO et al., 2018).

Em decorrência disso, considera-se imprescindível que os docentes possuam uma formação apropriada no que diz respeito às questões de gênero e sexualidade, considerando-se o seu papel social, como um profissional possuidor de um pensamento crítico e respeitoso pela diversidade humana em todas as suas especificidades (NOGUEIRA; FERREIRA; BARBOSA, 2019).

Dessa maneira, para que haja esta compreensão, admite-se que debater sobre igualdade de gênero no ambiente escolar é de fundamental importância. Para tal, é preciso discussões que busquem elaborar ações educativas a serem desempenhadas no cotidiano da escola, evitando-se assim, a desigualdade no tratamento de meninos e meninas na escola (NOGUEIRA; FERREIRA; BARBOSA, 2019).

Ainda é válido destacar que, em relação à estes questionamentos, reside a importância de uma formação que docentes consigam o embasamento teórico-metodológico para pensar a respeito destas questões que envolvem gênero e sexualidade (XAVIER FILHA, 2017). Enfim, é plausível afirmar que os docentes se tornaram peça fundamental para o despertar do senso crítico e do pensar dos discentes para uma sociedade com igualdade (FERREIRA, 2015).

É relevante trazer que um dos maiores desafios para os avanços na educação, seja nas modificações na legislação educacional, no plano curricular e nas metodologias didáticas. De modo especial na elaboração de conteúdos que não sejam apenas isentos de componentes discriminatórios explícitos, mas eficientes para a construção da igualdade (SOARES, 2019).

Nesta linha de investigação, é preciso citar que a educação no cenário contemporâneo vem sofrendo diversas transformações que requerem dos docentes e dos demais membros da comunidade educacional, sérias reflexões como questões sobre a sexualidade. Devendo, considerar que o sistema educacional brasileiro tem em sua história, vulnerabilidades e fracassos, onde este fato coloca os professores na obrigação de executar profundas reflexões e indagações, por meio de práticas discursivas, aos processos de aprendizagem empregados aos saberes adquiridos pela experiência e conhecimentos pedagógicos (LUTZ; NERY, 2020)ainda mais no âmbito de uma realidade moderno-líquida e de injustiça curricular. Da mesma forma, abordar-se a educação em risco abarca trabalhar-se a 
justiça curricular em seus novos temas. Considerando estes aspectos, a proposta da Roda de Conversa visa gerar questionamentos e reflexões pois buscar a transformação da realidade requer essencial conhecimento prévio. Propor-se uma roda de conversa abordando temas emergentes em educação permite fomentar a reflexão e questionamentos sobre a realidade vigente em sentido amplo de uma realidade de um mundo líquido, fundamentada em Bauman (2001.

\section{CONSIDERACÕ̃ES FINAIS}

As reflexões tecidas neste texto evidenciam que até este momento, persistem profundas impasses que separam os indivíduos, sobretudo no cenário da educação. Como também, contempla diversos preconceitos acerca dos comportamentos, atitudes, saberes e gestos. Logo, quando se discute sobre sexualidade na sociedade atual, imediatamente, se correlaciona com crenças, ideologias e imaginações empregadas para categorizar corpos humanos.

Neste cenário, percebe-se na grande maioria das vezes, temas associados à educação sexual e gênero são ignorados, favorecendo para o senso comum, assim sendo, a preservação de percepções equivocadas e preconceituosas que debilitam a interlocução entre a subjetividade, identidade e saúde. Com isso, muitas vezes ao lidar com questões relacionadas a gênero e sexualidade, os docentes, comumente, fazem o uso de uma abordagem moralizante, levando suas experiências e opiniões pessoais, sem subsídio teórico-conceitual.

Considera-se que não há como trabalhar no contexto educacional e ignorar as manifestações da sexualidade e a aceitação ao diferente, sendo que, são aspectos fundamentais do desenvolvimento dos indivíduos, agregados a dinâmica do ensino e aprendizagem. Nesse sentido, cabe salientar ainda a importância de políticas de equidade, a fim de promover um ambiente escolar mais saudável para todos os indivíduos envoltos no processo de ensino e aprendizagem.

\section{REFERÊNCIAS}

ALMEIDA, M. C. O.; VALE, C. S.; SILVA, C. C. G. A construção da identidade do aluno frente ao projeto lei de ideologia de gênero. Diversitas Journal, v. 5, n. 1, p. 603-614, 2020.

ARAUJO, M. F.; ROSSI, C. R.; TEIXEIRA, F. O saber fazer docente em educação para a sexualidade na educação básica: um paralelo entre Portugal e Brasil. Revista Ibero-Americana de Estudos em Educação, v. 14, n. esp.2, p. 1410-1426, 2019.

BORGES, R. C. V.; ROSSI, C. R. Educação em sexualidades e relações de gênero no contexto do ensino infantil: vivências possíveis. Revista Contexto \& Educação, v. 34, n. 108, p. 144-163, 2019. 
BRABO, T. S. A. M.; SILVA, M. E. F.; MACIEL, T. S. Gênero, sexualidades e educação: cenário das políticas educacionais sobre os direitos sexuais e reprodutivos de jovens e adolescentes. Práxis Educativa, v. 15, n. 1, p. 1-21, 2020.

CARDOSO, L. R. et al. Gênero em políticas públicas de educação e currículo: do direito às invenções. Revista e-Curriculum, v. 17, n. 4, p. 1479-1558, 2019.

DELFINO, L. L. Modos de aprender a ensinar sobre gênero nas aulas de história. Apontamentos sobre os relatos de experiências do PIBID/UNIFAL (2015-2016). História \& Ensino, v. 25, n. 2, p. 191-216, 2020.

FERRAZ, M. O. K.; ADDOR, N.; NASCIMENTO NETO, J. O. Políticas públicas de gênero na educação: uma análise para o desenvolvimento. Revista Eletrônica do Curso de Direito da UFSM, v. 14, n. 3, p. 1-32, 2019.

FERREIRA, M. P. Currículo, gênero e sexualidade: questões indispensáveis à formação docente. Revista Margens Interdisciplinar, v. 9, n. 12, p. 37-56, 2015.

FURLANETTO, M. F. et al. Educação sexual em escolas brasileiras: revisão sistemática da literatura. Cadernos de Pesquisa, v. 48, n. 168, p. 550-571, 2018.

LUGOBONI, L. F. et al. Modelos de gestão: uma revisão da literatura brasileira. CAFI - Contabilidade, Atuária, Finanças \& Informação, v. 3, n. 1, p. 83-102, 2020.

LUTZ, A.; NERY, M. C. R. Educação brasileira hoje: condições e contradições. Revista do Seminário de Educação de Cruz Alta - RS, v. 7, n. 1, p. 51-60, 2020.

NOGUEIRA, B.; FERREIRA, M. D. S.; BARBOSA, M. A Igualdade de gênero na perspectiva de professoras de uma escola pública. Redes - Revista Interdisciplinar do IELUSC, v. 2, n. 2, p. 13-24, 2019.

OLIVEIRA, A. L.; DIAS, A. F. Discursos sobre corpo, gênero e sexualidade na educação do Colégio de Aplicação da Universidade Federal de Sergipe. Revista e-Curriculum, v. 17, n. 2, p. 492-512, 2019.

PROBST, M.; KRAEMER, C. Gênero, afetividade e sexualidade: o que dizem os adolescentes das escolas públicas do vale do Itajaí (SC) sobre isso? Revista Prâksis, v. 1, n. 1, p. 156-172, 2020.

REMÍDIO, R. C. A.; SILVA, K.; MEIRELES, C. R. Educação e diversidade: trabalhando questões de gênero e sexualidade com adolescentes em escolas públicas. Mediação, v. 1, n. 9, p. 26-31, 2019. 
SEOANE, V.; SEVERINO, M. Género, sexualidades y educación. Intersecciones necesarias para una educación emancipadora. Descentrada, v. 3, n. 1, p. 1-6, 2019.

SOARES, A. G. Mapeamento de teses e dissertações sobre gênero, diversidade sexual e formação inicial docente no Brasil. Jornal de Políticas Educacionais, v. 13, n. 1, p. 1-26, 2019.

SOARES, F. F.; CHAVES, G.; FÉLIX, J. O que querem ensinar do nosso sexo? A influência do Congresso Nacional sobre gênero e sexualidade nas escolas. Revista Educação e Emancipação, v. 12, n. 1, p. 94-117, 2019.

TRENTIM, R. H. S.; VIEIRA, T. R. Educação inclusiva pela igualdade de oportunidades: Debate sobre gênero e sexualidade na escola. Akrópolis - Revista de Ciências Humanas da UNIPAR, v. 27, n. 2, p. 205-215, 2019.

XAVIER FILHA, C. Tecer e entretecer a vida: educação para as sexualidades e gêneros na formação docente. InterMeio: Revista do Programa de Pós-Graduação em Educação - UFMS, v. 23, n. 46, p. 215-236, 2017. 


\section{(). (1) (-)}

Este artigo é licenciado na modalidade acesso abertosob a Atribuição-Compartilhalgual CC BY-SA

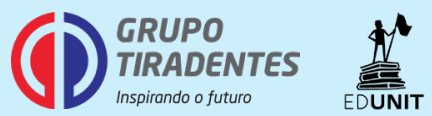

